\title{
Associations Between Symptoms and Quality of Life in Lumbar Degenerative Disease and Cognitive Dysfunction in a Japanese Community: A Cross- sectional Study
}

\section{Kazushige Koyama}

Hirosaki University Graduate school of Medicine

Kanichiro Wada ( $\sim$ wadak39@hirosaki-u.ac.jp)

Hirosaki University Graduate School of Medicine https://orcid.org/0000-0002-1112-5656

\section{Gentaro Kumagai}

Hirosaki University Graduate School of Medicine Hitoshi Kudo

Hirosaki University Graduate School of Medicine

\section{Sunao Tanaka}

Hirosaki University Graduate School of Medicine

\section{Toru Asari}

Hirosaki University Graduate School of Medicine

\section{Kazunari lhara}

Hirosaki University Graduate School of Medicine

\section{Shigeyuki Nakaji}

Hirosaki University Graduate School of Medicine

\section{Yasuyuki Ishibashi}

Hirosaki University Graduate School of Medicine

\section{Research article}

Keywords: Lumbar spinal stenosis, lumbar degenerative disease, cognitive impairment, community-based study, epidemiology

Posted Date: August 21st, 2020

DOl: https://doi.org/10.21203/rs.3.rs-55973/v1

License: (9) This work is licensed under a Creative Commons Attribution 4.0 International License. Read Full License 


\section{Abstract}

Background: Lumbar degenerative disease (LDD) and dementia are increasing in super-aging societies and are both related to physical dysfunction and pain. However, the relationship between these diseases remains unclear. This cross-sectional study aimed to investigate the rate of comorbidity of lumbar spinal stenosis (LSS) and mild cognitive impairment (MCl) by age and sex and clarify the association between LSS presence, LDD symptoms, quality of life (QOL) related to low back pain, and cognitive impairment in a Japanese population.

Methods: We enrolled 1097 participants (men 437; women 660; mean age 54.6 years) from a medical checkup program. LSS was diagnosed using a self-administered questionnaire, and LDD symptoms were evaluated using visual analog scale (VAS: low back pain, pain, numbness of the lower limb). QOL related to low back pain was evaluated using the Japanese Orthopedic Association Back-Pain Evaluation Questionnaire (JOABPEQ: pain, lumbar function, and gait function), and Kellgren-Lawrence grading was performed to evaluate lumbar degeneration using lateral radiographs of the lumbar spine. Cognitive function was measured using the Mini Mental State Examination (MMSE), and we defined $\mathrm{MCl}$ as a summary score of MMSE $£ 27$. Logistic and multiple liner regression analyses were performed to analyze the association between $\mathrm{MCl}$, summary score of MMSE and LSS factors.

Results: The comorbidity rate of $\mathrm{MCl}$ and LSS was $0.9 \%$ in men and $0.7 \%$ in women. It was $2.1 \%$ in those aged ${ }^{3} 65$ years in both sexes, and this rate increased with age. Lumbar function in JOABPEQ (OR 0.979, $95 \% \mathrm{Cl} 0.961$ to 0.998 ) and lower limb pain in VAS (OR 1.020,95\% Cl 1.002 to 1.039) were associated with $\mathrm{MCl}$ in men. The presence of LSS, lumbar function, and gait function in JOABPEQ were associated with MMSE in both sexes, while lower limb numbness and pain in VAS were associated with MMSE in men.

Conclusion: The comorbidity rate of LSS and $\mathrm{MCl}$ increased with age. The presence of LSS, certain symptoms of LDD, and deterioration of QOL due to low back pain were related to cognitive dysfunction. Treatment of LDD could help to improve both LDS symptoms and cognitive dysfunction.

\section{Background}

Lumbar degenerative disease (LDD), such as lumbar spinal stenosis (LSS), degenerative spondylolisthesis and spondylosis deformity, is more prevalent among middle-aged and elderly individuals. LDD causes low back pain, intermitted claudication, bladder and rectal disturbance, numbness and lower limb pain, and deterioration in muscle power of the lower limbs as well as standing and walking abilities [1-3]. The number of people whose quality of life (QOL) is impaired by LDD is expected to increase in a super-aging society.

Mild cognitive impairment $(\mathrm{MCl})$ is a pre-stage of dementia, and people with $\mathrm{MCl}$ are in a high-risk group for developing dementia [4]. However, $\mathrm{MCl}$ can be improved if risk factors of cognitive dysfunction are reduced $[5,6]$. Thus, reducing the risk of cognitive impairment is important to prevent the development of 
dementia. Several reports have shown that cognitive impairment is related with pain and physical dysfunctions [7-9], which are typical symptoms of musculoskeletal disease. Cognitive function certainly decays with age, thereby increasing the prevalence of $\mathrm{MCl}$ in the future.

Previous studies investigating the association between cognitive function and musculoskeletal diseases reported that $\mathrm{MCl}$ was related with the occurrence of knee osteoarthritis [10] and that delayed union of osteoporotic vertebral fracture decreased cognitive function [11]. However, the association between LDD and cognitive function remains unclear, although both LDD and cognitive impairment are related to pain and physical dysfunction. Hence, clarifying the relationship between LDD and cognitive impairment may be important for improving ADL in elderly people. This study aimed to investigate the rate of comorbidity of $\mathrm{MCl}$ and LSS by age and sex, and to clarify the relationship between $\mathrm{MCl} / \mathrm{MMSE}$ score and the risk factors of LDD-LSS presence, LDD symptom, QOL score depending on low back pain and radiographical lumbar degeneration in a community-dwelling Japanese population.

\section{Materials And Methods}

\section{Participants}

Our analysis was based on data collected from a medical checkup program in 2016. In brief, this program was initiated in 2005 , and it was conducted over a 10 -year period. In addition to orthopedic surgeons, gynecologists, urologists, endocrine physicians, cardiologist physicians, gastroenterologists, neurologists, and otolaryngologists were involved in this project. As one aspect of the multiple-focused check, we collected questionnaires and radiographic images related to musculoskeletal disorder.

For this cross-sectional study, 1149 participants were enrolled. Participants were asked to complete some self-administered questionnaires assessing their daily habits, medical histories, and LDD. They also underwent a cognitive screening test and a lateral lumbar radiograph in the neutral position. We excluded those who did not answer the questionnaire entirely, did not undergo cognitive screening test and radiographic examination, or had medical histories of lumbar spine surgeries. Of all participants, 52 were excluded (19 men, 33 women). Of those excluded, 36 (13 men, 23 women) did not answer questionnaires entirely, 13 (4 men, 9 women) did not undergo radiography, and 3 ( 2 men, 1 woman) had previous lumbar surgery. Finally, 1097 people (20-93 years old, 437 men, 660 women) were included in this study. The mean ages were 53.6 years old in men and 55.3 years old in women. All participants were provided a thorough explanation that the data collected would be analyzed, and gave written informed consent.

\section{Diagnosis of LSS}

LSS was detected using self-administered questionnaires consisting 15 questions associated with neurological disorders. We diagnosed LSS when the scores were 13 points or greater (sensitivity: 84\%, specificity: 78\%) [12]. 


\section{Evaluation of cognitive function}

Cognitive function was measured using the Mini Mental State Examination (MMSE) [13]. This is a 30item cognitive screening test that measures orientation, registration, short-term memory, attention and concentration, and language and construction capacity. The full score of MMSE is 30 points, with 0 being the worst cognitive function. We defined the participant as having $\mathrm{MCl}$ when MMSE was 27 points or less, because this cut-off value had the greatest sensitivity (66.3\%) and specificity $(72.9 \%)$ of diagnosing $\mathrm{MCl}$ in a previous report [14]. We defined the participants whose MMSE was score 27 points or less as $\mathrm{MCl}+$ group, and the participants whose MMSE score was over 27 points as $\mathrm{MCl}$ - group.

\section{Assessment of symptoms of LDD, and quality of life associated with low back pain}

The severities of the symptoms of LDD were evaluated with the visual analogue scale (VAS), for the most severe low back pain, lower limb pain and numbness during the past three months. The most severe score is $100 \mathrm{~mm}$, and $0 \mathrm{~mm}$ means no symptoms.

Deterioration of quality of life (QOL) due to low back pain was evaluated using the Japanese Orthopedics Association Back Pain Evaluation Questionnaire (JOABPEQ) [15]. There have been several reports that JOABPEQ was useful for evaluating QOL in patients with lumbar disc herniation, LSS, and other lumbar diseases [16-18]. It consists of five domains: pain, gait function, lumbar function, social life, and mentality, and each domain is scored out of 100 points. Three of the five domains: pain, gait function and lumbar function were used for analysis in this study. Research assistants supported the participants who could not answer these questionnaires by themselves.

\section{Measurement of lumbar degeneration on radiography}

Lateral radiographs of the lumbar spine were taken, with the participants standing naturally, with their forearms crossed and hands on the chest. Radiographs were evaluated by a single orthopedic surgeon (KK) using Kellgren-Lawrence grading (KL) [19] in each intervertebral level (L1/2, L2/3, L3/4, L4/5, and $L 5 / S 1)$. To determine the severities of lumbar degeneration, the values of $K L$ were summed from $L 1 / 2$ to $\mathrm{L} 5 / \mathrm{S}$. According to this summed value, 0 corresponded to a normal lumbar spine and 20 expressed the most severe degenerative lumbar spine [20].

\section{Medical histories and daily habits}

All participants provided data related to their medical histories and daily habits which were previously reported as related to cognitive impairment [21-25]. Medical histories related to diabetes mellitus (DM), hypertension (HT), and depression were collected. We collected data pertaining to their duration of 
education ( 6 to 20 years), daily smoking habits (0, ex-smoker or never smoked; 1 , current smoker), alcohol consumption ( 0 , ex-drinker or never drank or social drinker; 1 , habitual drinker) and exercise ( 0 , no exercise habit; 1 , having exercise habits over 2 times during one week).

\section{Statistical analyses}

Descriptive statistics were used to investigate the prevalence of $\mathrm{MCl}$ and LSS by age and sex. To compare characteristics between $\mathrm{MCl}+$ and $\mathrm{MCl}$ - groups, we used the Mann-Whitney $\mathrm{U}$ test with the presence of $\mathrm{MCl}$ as the dependent variable and age, BMI, VAS, JOABPEQ, summed $\mathrm{KL}$, and education periods as independent variables. To analyze the correlation between $\mathrm{MCl}$ and LDD parameters, logistic regression analysis was performed with $\mathrm{MCl}$ as the dependent variable and the presence of LSS, VAS, JOABPEQ and summed KL grades as the independent variables. For adjusting for age, duration of education, DM, HT, depression, smoking, alcohol consumption, and exercise, they were also included as independent variables. To analyze the correlation between MMSE and LDD parameters, multiple linear regression analysis was performed with MMSE as the dependent variable and the presence of LSS, VAS, JOABPEQ, and summed $\mathrm{KL}$ grades as the independent variables. All statistical tests were performed using SPSS ver. 22.0 (SPSS Inc., Chicago, IL, USA), and statistical significant was set at 0.05.

\section{Results}

\section{Prevalence of $\mathrm{MCl}$ and LSS by age and sex}

In men, 48 individuals (11\%) had MCl. The prevalence of $\mathrm{MCl}$ increased with age and was $29 \%(35 / 123)$ in those aged ${ }^{3} 65$ years. Eleven individuals (2.5\%) were diagnosed with LSS and the prevalence of LSS also increased with age. In women, 45 individuals (6.8\%) had $\mathrm{MCl}$. The prevalence increased with age and was $18 \%(37 / 211)$ in those aged ${ }^{3} 65$ years. Twenty individuals $(3.0 \%)$ were diagnosed with LSS. The comorbidity rate of $\mathrm{MCl}$ and LSS was $0.8 \%$ in all participants, $0.9 \%$ in men and $0.7 \%$ in women (Table 1 ). The comorbidity rate was $2.1 \%(7 / 334)$ in those aged ${ }^{3} 65$ years, and increased with age. The rate of $\mathrm{MCl}$ was $29 \%(9 / 31)$ in participants with LSS in both sexes, $36 \%(4 / 11)$ in men, and $25 \%(5 / 20)$ in women. The rate of LSS was 9.8\% (9/92) in participants with $\mathrm{MCl}$ in both sexes, $8.5 \%(4 / 47)$ in men, and $11 \%$ $(5 / 45)$ in women. 
Table 1

$\mathrm{MCl}$ and LSS prevalence, JOABPEQ, VAS, medical histories and daily habits by age and sex.

\begin{tabular}{|c|c|c|c|c|c|c|c|c|}
\hline Men (437) & Total & & $\begin{array}{l}20 s \\
(25)\end{array}$ & & $\begin{array}{l}30 s \\
(83)\end{array}$ & & $\begin{array}{l}40 s \\
(72)\end{array}$ & \\
\hline BMI & 23.7 & \pm 3.0 & 22.9 & \pm 3.9 & 23.3 & \pm 3.2 & 24.6 & \pm 3.2 \\
\hline LSS & 11 & $(2.5)$ & 0 & $(0)$ & 1 & $(1.2)$ & 1 & (1.4) \\
\hline $\mathrm{MCl}$ & 47 & (11) & 1 & $(4.0)$ & 0 & (0) & 3 & $(4.2)$ \\
\hline $\begin{array}{l}\text { Comorbidity of LSS } \\
\text { and } \mathrm{MCl}\end{array}$ & 4 & $(0.9)$ & 0 & $(0)$ & 0 & (0) & 0 & (0) \\
\hline MMSE & 29.2 & \pm 1.6 & 29.5 & \pm 1.2 & 29.7 & \pm 0.5 & 29.6 & \pm 0.9 \\
\hline \multicolumn{9}{|l|}{ VAS (mm) } \\
\hline Low back pain & 17.1 & $\stackrel{ \pm}{21.9}$ & 5.4 & \pm & 15.4 & \pm 19.4 & 17.2 & \pm 23.3 \\
\hline Pain of lower limb & 5.1 & \pm & 3.4 & \pm & 3.3 & \pm 10.4 & 4.4 & \pm 9.7 \\
\hline $\begin{array}{l}\text { Numbness of lower } \\
\text { limb }\end{array}$ & 4.6 & \pm & 1.1 & \pm 3.2 & 3.0 & \pm 10.4 & 4.1 & \pm 10.0 \\
\hline \multicolumn{9}{|l|}{ JOABPEQ } \\
\hline Pain & 85.6 & $\stackrel{ \pm}{26.5}$ & 93.1 & $\stackrel{ \pm}{20.7}$ & 86.2 & \pm 24.9 & 87.5 & \pm 25.5 \\
\hline Lumbar function & 93.0 & \pm & 97.7 & \pm 5.7 & 98.0 & \pm 8.7 & 97.0 & \pm 7.0 \\
\hline Gait function & 94.8 & \pm & 100.0 & \pm 0 & 98.7 & \pm 6.1 & 99.4 & \pm 3.5 \\
\hline $\mathrm{KL}$ & 4.8 & \pm 4.3 & 1.0 & \pm 1.4 & 1.6 & \pm 2.2 & 2.5 & \pm 2.7 \\
\hline $\begin{array}{l}\text { Education periods } \\
\text { (year) }\end{array}$ & 12.2 & \pm & 13.2 & \pm 2.2 & 12.7 & \pm 1.6 & 12.5 & \pm 1.4 \\
\hline DM & 33 & (7.5) & 0 & $(0)$ & 0 & (0) & 2 & (2.8) \\
\hline HT & 125 & $(29)$ & 0 & $(0)$ & 2 & (2.4) & 8 & (11) \\
\hline Depression & 3 & $(0.7)$ & 0 & $(0)$ & 0 & (0) & 0 & (0) \\
\hline Smoking & 127 & $(29)$ & 8 & (32) & 40 & (48) & 22 & (31) \\
\hline Alcohol & 305 & $(70)$ & 7 & $(28)$ & 63 & (76) & 46 & (64) \\
\hline Exercise & 80 & (18) & 5 & $(20)$ & 14 & (17) & 11 & (15) \\
\hline Men (437) & $\begin{array}{l}50 s \\
(83)\end{array}$ & & $\begin{array}{l}60 s \\
(106)\end{array}$ & & $\begin{array}{l}70 s \\
(50)\end{array}$ & & $\begin{array}{l}\text { over } 80 \\
\text { (18) }\end{array}$ & \\
\hline
\end{tabular}




\begin{tabular}{|c|c|c|c|c|c|c|c|c|}
\hline BMI & 23.6 & \pm 2.6 & 23.7 & \pm 2.9 & 23.4 & \pm 2.6 & 23.7 & \pm 3.9 \\
\hline LSS & 2 & $(2.4)$ & 4 & (3.8) & 1 & $(2.0)$ & 2 & $(11)$ \\
\hline $\mathrm{MCl}$ & 0 & $(0)$ & 18 & (17) & 15 & (30) & 10 & $(56)$ \\
\hline $\begin{array}{l}\text { Comorbidity of LSS } \\
\text { and } \mathrm{MCl}\end{array}$ & 0 & $(0)$ & 2 & (8.0) & 1 & $(4.0)$ & 1 & $(4.0)$ \\
\hline MMSE & 29.7 & \pm 0.5 & 28.9 & \pm 1.7 & 28.2 & \pm 2.1 & 26.1 & \pm 3.1 \\
\hline \multicolumn{9}{|l|}{ VAS (mm) } \\
\hline Low back pain & 18.3 & \pm 23.6 & 18.1 & \pm 20.8 & 18.9 & \pm 22.7 & 23.1 & \pm 30.2 \\
\hline Pain of lower limb & 4.7 & \pm 13.4 & 7.2 & \pm 18.0 & 7.0 & \pm 17.7 & 3.7 & \pm 11.6 \\
\hline $\begin{array}{l}\text { Numbness of lower } \\
\operatorname{limb}\end{array}$ & 3.3 & \pm 12.3 & 6.0 & \pm 15.3 & 7.1 & \pm 19.7 & 9.0 & \pm 21.0 \\
\hline \multicolumn{9}{|l|}{ JOABPEQ } \\
\hline Pain & 86.1 & \pm 26.3 & 83.7 & \pm 27.0 & 83.1 & \pm 29.1 & 79.4 & \pm 35.1 \\
\hline Lumbar function & 94.9 & \pm 10.7 & 88.7 & \pm 18.8 & 86.3 & \pm 17.0 & 82.9 & \pm 20.1 \\
\hline Gait function & 97.5 & \pm 8.4 & 91.7 & \pm 17.8 & 90.0 & \pm 16.0 & 69.4 & \pm 29.2 \\
\hline $\mathrm{KL}$ & 4.7 & \pm 3.1 & 7.7 & \pm 4.3 & 7.5 & \pm 3.7 & 10.2 & \pm 4.7 \\
\hline $\begin{array}{l}\text { Education periods } \\
\text { (year) }\end{array}$ & 12.2 & \pm 1.7 & 12.3 & 2.2 & 10.8 & \pm 2.2 & 10.3 & \pm 2.7 \\
\hline DM & 3 & (3.6) & 18 & (17) & 6 & (12) & 4 & $(22.2)$ \\
\hline HT & 18 & (22) & 51 & (48) & 34 & (68) & 12 & (68) \\
\hline Depression & 1 & $(1.2)$ & 2 & (1.9) & 0 & $(0)$ & 0 & $(0)$ \\
\hline Smoking & 33 & $(40)$ & 20 & (19) & 4 & $(8.0)$ & 0 & (0) \\
\hline Alcohol & 65 & (78) & 78 & (74) & 35 & (70) & 11 & $(61)$ \\
\hline Exercise & 11 & (13) & 17 & (16) & 19 & (38) & 3 & (17) \\
\hline Women (660) & Total & & $\begin{array}{l}20 s \\
(34)\end{array}$ & & $\begin{array}{l}30 s \\
(95)\end{array}$ & & $\begin{array}{l}40 s \\
(108)\end{array}$ & \\
\hline BMI & 22.5 & \pm 3.5 & 21.0 & \pm 4.0 & 20.9 & \pm 3.6 & 22.6 & \pm 3.9 \\
\hline LSS & 20 & (3.0) & 0 & (0) & 0 & $(0)$ & 0 & $(0)$ \\
\hline $\mathrm{MCl}$ & 45 & (6.8) & 0 & (0) & 1 & (1.1) & 1 & $(0.9)$ \\
\hline $\begin{array}{l}\text { Comorbidity of LSS } \\
\text { and } \mathrm{MCl}\end{array}$ & 5 & $(0.8)$ & 0 & (0) & 0 & $(0)$ & 0 & $(0)$ \\
\hline MMSE & 29.4 & \pm 1.3 & 29.8 & \pm 0.5 & 29.8 & \pm 0.5 & 29.8 & \pm 0.6 \\
\hline
\end{tabular}


VAS (mm)

\begin{tabular}{|c|c|c|c|c|c|c|c|c|}
\hline Low back pain & 18.3 & \pm 22.1 & 13.6 & \pm 20.8 & 12.1 & \pm 17.3 & 17.0 & \pm 21.7 \\
\hline Pain of lower limb & 6.3 & \pm 15.6 & 1.2 & \pm 5.7 & 1.4 & \pm 5.8 & 6.2 & \pm 16.5 \\
\hline $\begin{array}{l}\text { Numbness of lower } \\
\text { limb }\end{array}$ & 5.1 & \pm 14.6 & 0.2 & \pm 1.0 & 0.7 & \pm 3.3 & 4.2 & \pm 12.1 \\
\hline \multicolumn{9}{|l|}{ JOABPEQ } \\
\hline Pain & 86.7 & \pm 23.9 & 91.6 & \pm 18.0 & 93.2 & \pm 16.1 & 88.5 & \pm 22.4 \\
\hline Lumbar function & 90.5 & \pm 17.0 & 97.1 & \pm 10.4 & 96.9 & \pm 9.0 & 94.8 & \pm 12.2 \\
\hline Gait function & 90.6 & \pm 19.2 & 98.1 & \pm 6.4 & 98.7 & \pm 5.0 & 97.2 & \pm 8.7 \\
\hline $\mathrm{KL}$ & 3.4 & \pm 3.6 & 1.3 & \pm 1.8 & 1.0 & \pm 1.8 & 1.4 & \pm 1.9 \\
\hline $\begin{array}{l}\text { Education periods } \\
\text { (year) }\end{array}$ & 12.1 & \pm 12.1 & 13.8 & \pm 1.5 & 13.0 & \pm 1.6 & 12.9 & \pm 1.6 \\
\hline DM & 25 & (3.8) & 1 & (2.9) & 1 & $(1.1)$ & 0 & $(0)$ \\
\hline HT & 167 & $(25)$ & 1 & $(2.9)$ & 1 & $(1.1)$ & 7 & $(6.5)$ \\
\hline Depression & 4 & $(0.6)$ & 0 & (0) & 0 & $(0)$ & 0 & $(0)$ \\
\hline Smoking & 70 & (11) & 3 & (8.8) & 19 & $(20)$ & 21 & (19) \\
\hline Alcohol & 183 & $(28)$ & 6 & (18) & 35 & (37) & 43 & $(40)$ \\
\hline Exercise & 109 & $(17)$ & 2 & (5.9) & 15 & (16) & 16 & (15) \\
\hline Women (660) & $\begin{array}{l}50 s \\
(125)\end{array}$ & & $\begin{array}{l}60 s \\
(178)\end{array}$ & & $\begin{array}{l}70 s \\
(94)\end{array}$ & & $\begin{array}{l}\text { over } 80 \\
\text { (26) }\end{array}$ & \\
\hline BMI & 22.3 & \pm 2.8 & 22.9 & \pm 3.3 & 23.5 & \pm 3.6 & 23.3 & \pm 2.7 \\
\hline LSS & 5 & $(4.0)$ & 4 & $(2.2)$ & 7 & $(7.4)$ & 4 & (15) \\
\hline $\mathrm{MCl}$ & 3 & $(2.4)$ & 13 & (7.3) & 16 & $(17)$ & 11 & $(42)$ \\
\hline $\begin{array}{l}\text { Comorbidity of LSS } \\
\text { and } \mathrm{MCl}\end{array}$ & 1 & $(0.8)$ & 0 & (0) & 2 & $(2.1)$ & 2 & (7.7) \\
\hline MMSE & 29.6 & \pm 0.8 & 29.3 & \pm 1.2 & 28.4 & \pm 1.8 & 27.7 & \pm 2.3 \\
\hline \multicolumn{9}{|l|}{ VAS $(\mathrm{mm})$} \\
\hline Low back pain & 17.9 & \pm 21.7 & 17.2 & \pm 20.8 & 25.2 & \pm 23.9 & 35.9 & \pm 31.1 \\
\hline Pain of lower limb & 7.6 & \pm 17.4 & 6.3 & \pm 14.9 & 8.7 & \pm 16.2 & 15.5 & \pm 28.3 \\
\hline $\begin{array}{l}\text { Numbness of lower } \\
\text { limb }\end{array}$ & 7.0 & \pm 16.7 & 4.9 & \pm 13.9 & 8.3 & \pm 18.1 & 13.2 & \pm 27.8 \\
\hline JOABPEQ & & & & & & & & \\
\hline
\end{tabular}




\begin{tabular}{|lllllllll|}
\hline Pain & 86.4 & \pm 24.1 & 88.3 & \pm 22.1 & 77.1 & \pm 30.1 & 74.7 & \pm 32.7 \\
\hline \multicolumn{1}{|c}{ Lumbar function } & 92.0 & \pm 14.0 & 89.1 & \pm 16.4 & 80.6 & \pm 24.0 & 78.5 & \pm 25.5 \\
\hline \multicolumn{1}{|c}{ Gait function } & 94.5 & \pm 11.8 & 89.1 & \pm 18.7 & 77.4 & \pm 26.3 & 61.5 & \pm 37.1 \\
\hline KL & 2.7 & \pm 2.8 & 4.4 & \pm 3.1 & 6.7 & \pm 3.7 & 8.8 & \pm 4.9 \\
\hline $\begin{array}{l}\text { Education periods } \\
\text { (year) }\end{array}$ & 12.7 & \pm 1.4 & 11.6 & \pm 1.7 & 10.4 & \pm 1.8 & 9.8 & \pm 2.5 \\
\hline DM & 7 & $(5.6)$ & 5 & $(2.8)$ & 9 & $(9.6)$ & 2 & $(7.7)$ \\
HT & 20 & $(16)$ & 66 & $(37)$ & 52 & $(55)$ & 20 & $(77)$ \\
\hline Depression & 1 & $(0.8)$ & 3 & $(1.7)$ & 0 & $(0)$ & 0 & $(0)$ \\
\hline Smoking & 15 & $(12)$ & 11 & $(6.2)$ & 1 & $(1.1)$ & 0 & $(0)$ \\
\hline Alcohol & 42 & $(34)$ & 40 & $(23)$ & 11 & $(12)$ & 6 & $(23)$ \\
\hline Exercise & 23 & $(18)$ & 30 & $(17)$ & 21 & $(22)$ & 6 & $(23)$ \\
\hline
\end{tabular}

Data are presented as mean \pm SD or as $\mathrm{n}(\%)$. MCl, mild cognitive impairment; LSS, lumbar spinal canal stenosis; JOABPEQ, Japan Orthopedics Association Back Pain Evaluation Questionnaires; VAS, visual analog scale; KL, Kellgren-Lawrence grade; MMSE, Mini Mental State Examination; MCl, mild cognitive impairment; $\mathrm{DM}$, diabetes mellitus; $\mathrm{HT}$, hyper tension

\section{Comparison of characteristics between $\mathrm{MCl}+$ and $\mathrm{MCl}-$ groups}

We investigated the differences of parameters between the group with $\mathrm{MCl}$ and that without $\mathrm{MCl}$ using the Mann-Whitney U test. Age and the prevalence of LSS and KL were significantly higher in the $\mathrm{MCl}+$ group than in the $\mathrm{MCl}-$ group in both sexes. In men, lumbar function and gait function of JOABPEQ were lower in the $\mathrm{MCl}+$ than in the $\mathrm{MCl}$ - group. In women, all three domains of JOABPEQ were lower in the $\mathrm{MCl}+$ group than in the $\mathrm{MCl}$ - group, and pain and numbness of lower limb of VAS were higher in the $\mathrm{MCl}+$ group than in the $\mathrm{MCl}$ - group (Table 2). 
Table 2

Differences in demographic characteristics between groups with and without $\mathrm{MCl}$.

\begin{tabular}{|c|c|c|c|c|c|}
\hline \multirow[t]{2}{*}{ Men (437) } & \multicolumn{2}{|l|}{$\mathrm{MCl}-(389)$} & \multicolumn{2}{|l|}{$\mathrm{MCl}+(48)$} & \multirow[t]{2}{*}{$\mathrm{p}$} \\
\hline & Mean or (n) & SD or (\%) & Mean or (n) & SD or $(\%)$ & \\
\hline Age & 51.4 & 14.8 & 70.7 & 13.0 & $<0.001$ \\
\hline BMI & 23.7 & 3.0 & 23.3 & 3.2 & 0.32 \\
\hline LSS & (7) & $(1.8)$ & (4) & $(8.3)$ & 0.026 \\
\hline \multicolumn{6}{|l|}{ JOABPEQ } \\
\hline Pain & 86.3 & 25.6 & 79.8 & 32.1 & 0.082 \\
\hline Lumbar function & 94.3 & 12.2 & 82.1 & 22.7 & $<0.001$ \\
\hline Gait function & 96.1 & 12.3 & 84.1 & 22.2 & $<0.001$ \\
\hline \multicolumn{6}{|l|}{ VAS (mm) } \\
\hline Low back pain & 16.5 & 21.4 & 21.8 & 25.4 & 0.11 \\
\hline Pain of lower limb & 4.5 & 12.3 & 10.6 & 23.5 & 0.19 \\
\hline Numbness of lower limb & 3.9 & 11.6 & 9.8 & 24.3 & 0.44 \\
\hline $\mathrm{KL}$ & 4.4 & 4.3 & 8.4 & 4.4 & $<0.001$ \\
\hline Education periods (year) & 12.4 & 2.0 & 10.6 & 2.6 & $<0.001$ \\
\hline DM & (26) & $(6.7)$ & (7) & $(15)$ & 0.056 \\
\hline HT & (97) & $(25)$ & $(28)$ & $(58)$ & $<0.001$ \\
\hline Depression & (3) & $(0.8)$ & $(0)$ & (0) & 0.72 \\
\hline Smoking & (119) & (31) & (8) & (17) & 0.036 \\
\hline Alcohol & (274) & (70) & (31) & $(65)$ & 0.33 \\
\hline Exercise & (72) & (19) & (8) & (17) & 0.51 \\
\hline \multirow[t]{2}{*}{ Women (660) } & MCl- (615) & & $\mathrm{MCl}+(45)$ & & $\mathrm{p}$ \\
\hline & Mean or (n) & SD or (\%) & Mean or (n) & SD or $(\%)$ & \\
\hline Age & 54.1 & 15.1 & 71.2 & $10 . .6$ & $<0.001$ \\
\hline BMI & 22.4 & 3.5 & 22.9 & 3.4 & 0.13 \\
\hline LSS & (15) & $(2.4)$ & (5) & $(11)$ & 0.01 \\
\hline \multicolumn{6}{|l|}{ JOABPEQ } \\
\hline Pain & 87.4 & 23.2 & 77.5 & 30.7 & 0.009 \\
\hline
\end{tabular}




\begin{tabular}{|llllll|}
\hline Lumbar function & 91.4 & 15.6 & 77.6 & 27.4 & $<0.001$ \\
\hline Gait function & 91.8 & 17.7 & 74.0 & 29.2 & $<0.001$ \\
\hline VAS (mm) & & & & & \\
\hline Low back pain & 17.9 & 21.8 & 22.8 & 26.5 & 0.18 \\
\hline Pain of lower limb & 5.8 & 15.8 & 12.2 & 21.0 & 0.003 \\
\hline Numbness of lower limb & 4.7 & 13.7 & 11.0 & 23.3 & 0.003 \\
\hline KL & 3.2 & 3.5 & 6.2 & 3.7 & $<0.001$ \\
\hline Education periods (year) & 12.2 & 1.9 & 10.4 & 1.7 & $<0.001$ \\
\hline DM & $(23)$ & $(3.7)$ & $(2)$ & $(4.4)$ & 0.53 \\
\hline HT & $(141)$ & $(23)$ & $(26)$ & $(58)$ & $<0.001$ \\
\hline Depression & $(4)$ & $(0.7)$ & $(0)$ & $(0)$ & 0.76 \\
\hline Smoking & $(68)$ & $(11)$ & $(2)$ & $(4.4)$ & 0.13 \\
\hline Alcohol & $(175)$ & $(29)$ & $(8)$ & $(18)$ & 0.091 \\
\hline Exercise & $(101)$ & $(16)$ & $(8)$ & $(18)$ & 0.48 \\
\hline
\end{tabular}

Date are presented as mean $\pm \mathrm{SD}$ or as $\mathrm{n}(\%)$. Comparison between groups with and without $\mathrm{MCl}$ using Mann-Whitney U test. MCl, mild cognitive impairment; LSS, lumbar spinal canal stenosis; JOABPEQ, Japan Orthopedics Association Back Pain Evaluation Questionnaires; VAS, visual analog scale; KL, Kellgren-Lawrence grade; MMSE, Mini Mental State Examination; MCl, mild cognitive impairment; DM, diabetes mellitus; $\mathrm{HT}$, hyper tension

\section{The association between presence of LSS, symptoms of $L D D, Q O L$ related to $L D D$ and $\mathrm{MCl}$}

We showed the association between LDD factors (presence of LSS, symptoms related to LDD, and QOL score related to $L D D$ ) and $\mathrm{MCl}$ using logistic regression analysis with $\mathrm{MCl}$ as the dependent variable. In men, lumbar function of JOABPEQ (OR $0.979,95 \% \mathrm{Cl} 0.961$ to 0.998$)$ and pain of lower limb of VAS (OR $1.020,95 \% \mathrm{Cl} 1002$ to 1.039 ) were significantly associated with $\mathrm{MCl}$. In women, there was no significant relationship between $\mathrm{MCl}$ and any factors related to LDD (Table 3). 
Table 3

The impact of parameters related to LDD on $\mathrm{MCl}$

\begin{tabular}{|c|c|c|c|c|}
\hline Men & OR & $95 \% \mathrm{Cl}$ & & $\mathrm{p}$ \\
\hline LSS & & & & 0.14 \\
\hline \multicolumn{5}{|l|}{ JOABPEQ } \\
\hline Pain & & & & 0.49 \\
\hline Lumbar function & 0.979 & 0.961 & - 0.998 & 0.027 \\
\hline Gait function & & & & 0.54 \\
\hline \multicolumn{5}{|l|}{ VAS } \\
\hline Low back pain & & & & 0.61 \\
\hline Pain of lower limb & 1.020 & 1.002 & - 1.039 & 0.032 \\
\hline Numbness of lower limb & & & & 0.17 \\
\hline KL & & & & 0.22 \\
\hline Women & OR & $95 \% \mathrm{Cl}$ & & $\mathrm{p}$ \\
\hline LSS & & & & 0.29 \\
\hline \multicolumn{5}{|l|}{ JOABPEQ } \\
\hline Pain & & & & 0.48 \\
\hline Lumbar function & & & & 0.087 \\
\hline Gait function & & & & 0.20 \\
\hline \multicolumn{5}{|l|}{ VAS } \\
\hline Low back pain & & & & 0.37 \\
\hline Pain of lower limb & & & & 0.30 \\
\hline Numbness of lower limb & & & & 0.41 \\
\hline $\mathrm{KL}$ & & & & 0.87 \\
\hline
\end{tabular}

Logistic regression analysis was performed with $\mathrm{MCl}$ as the dependent variable. Factors related to LDD were independent variables. For adjusting for age, education periods, DM, HT, depression, smoking, alcohol consumption and exercise were also included as independent variables. $\mathrm{MCl}$, mild cognitive impairment; LDD, degenerative disease of the lumbar; LSS, lumbar spinal canal stenosis; JOABPEQ, Japan Orthopedics Association Back Pain Evaluation Questionnaires; VAS, visual analog scale; KL, Kellgren-Lawrence grade 


\section{The association between presence of LSS, symptoms of $L D D, Q O L$ related to $L D D$ and $M M S E$}

We showed the association between the factors of LDD and MMSE using multiple linear regression analysis with MMSE as the dependent variable. The presence of LSS $(\beta=-0.214,95 \% \mathrm{Cl}-3.018$ to -1.344$)$, lumbar function and gait function of JOABPEQ (lumbar function: $\beta=0.161,95 \% \mathrm{Cl} 0.008$ to 0.028 ; gait function: $\beta=0.106,95 \% \mathrm{Cl} 0.002$ to 0.022 ) and VAS of lower limb symptoms (pain of lower limb: $\beta=-0.141$, $95 \% \mathrm{Cl}-0.026$ to -0.007 ; numbness of lower limb: $\beta=-0.105,95 \% \mathrm{Cl}-0.022$ to -0.002 ) were related to MMSE significantly in men. The presence of LSS $(\beta=-0.093,95 \% \mathrm{Cl}-1.211$ to -0.168$)$ and two domains of JOABPEQ (lumbar function: $\beta=0.164,95 \% \mathrm{Cl} 0.007$ to 0.018 ; gait function: $\beta=0.149,95 \% \mathrm{Cl} 0.005$ to 0.015 ) were associated with MMSE significantly in women (Table 4). 
Table 4

The impact of parameters related to LDD on MMSE

\begin{tabular}{|c|c|c|c|c|c|}
\hline Men & $\beta$ & $95 \% \mathrm{Cl}$ & & & $p$ \\
\hline LSS & -0.214 & -3.018 & - & -1.344 & $<0.001$ \\
\hline \multicolumn{6}{|l|}{ JOABPEQ } \\
\hline Pain & & & & & 0.063 \\
\hline Lumbar function & 0.161 & 0.008 & - & 0.028 & $<0.001$ \\
\hline Gait function & 0.106 & 0.002 & - & 0.022 & 0.009 \\
\hline \multicolumn{6}{|l|}{ VAS } \\
\hline Low back pain & & & & & 0.25 \\
\hline Pain of lower limb & -0.141 & -0.026 & - & -0.007 & 0.001 \\
\hline Numbness of lower limb & -0.105 & -0.022 & - & -0.002 & 0.015 \\
\hline $\mathrm{KL}$ & & & & & 0.66 \\
\hline Women & $\beta$ & $95 \% \mathrm{Cl}$ & & & $\mathrm{p}$ \\
\hline LSS & -0.093 & -1.211 & - & -0.168 & 0.010 \\
\hline \multicolumn{6}{|l|}{ JOABPEQ } \\
\hline Pain & & & & & 0.27 \\
\hline Lumbar function & 0.164 & 0.007 & - & 0.018 & $<0.001$ \\
\hline Gait function & 0.149 & 0.005 & - & 0.015 & $<0.001$ \\
\hline \multicolumn{6}{|l|}{ VAS } \\
\hline Low back pain & & & & & 0.72 \\
\hline Pain of lower limb & & & & & 0.27 \\
\hline Numbness of lower limb & & & & & 0.31 \\
\hline $\mathrm{KL}$ & & & & & 0.28 \\
\hline
\end{tabular}

Multiple linear regression analysis was performed with MMSE as the dependent variable, and factors related to LDD as independent variables. For adjusting for age, education periods, $D M, H T$, depression, smoking, alcohol consumption and exercise, they were also included as independent variables. LDD, degenerative disease of the lumbar; MMSE, Mini Mental State Examination; LSS, lumbar spinal canal stenosis; JOABPEQ, Japan Orthopedics Association Back Pain Evaluation Questionnaires; VAS, visual analog scale; KL, Kellgren-Lawrence grade 


\section{Discussion}

\section{Summary of the current study}

This population-based study was conducted to clarify the relationship between LDD and cognitive impairment. Initially, we found that the rate of comorbidity of $\mathrm{MCl}$ and LSS was $2.1 \%$ in those aged ${ }^{3} 65$ years. Second, we analyzed the relationship between LSS presence, LDD symptoms, deterioration of QOL due to low back pain, radiographical lumbar degenerations, and cognitive impairment. Lower limb pain and deterioration of QOL due to low back pain were significantly associated with $\mathrm{MCl}$ in men. LSS presence, and deterioration of QOL due to low back pain were significantly related to MMSE in both sexes, and pain and numbness of the lower limb were significantly associated with MMSE in men.

\section{Prevalence of $\mathrm{MCl}$ and LSS, comorbidity of $\mathrm{MCl}$ and LSS}

The prevalence of $\mathrm{MCl}$ and LSS in general populations have been reported previously. The prevalence of $\mathrm{MCl}$ was $3.0 \%$ to $42 \%$ [26, 27], and had a strong association with aging [28]. Here, the prevalence of $\mathrm{MCl}$ was $8.5 \%$, and had relation with aging. The range of prevalence of $\mathrm{MCl}$ was great in this and previous population studies, one reason being that the diagnostic tools used for $\mathrm{MCl}$ were different: such as Clinical Dementia Rating, MMSE, Montreal Cognitive Assessment, Psychogeriatric Assessment Scale, or Wechsler Memory Scale-Revised. We defined $\mathrm{MCl}$ as a summary score of MMSE $£ 27$ in this study. MMSE is a useful screening tool for evaluating cognitive function. Thus, this study's results may be useful as base data for screening for cognitive impairment in a medical checkup program. Moreover, the ageranges of the subjects were different, and major cut-off age was 65 years old in previous studies. We collected data from the participants whose age-range was from 20 years old to 93 years old in this study. Hence, the prevalence of $\mathrm{MCl}$ we showed would be reasonable compared with past reports.

The prevalence of LSS was $10.1 \%$ in men and $8.9 \%$ in women and was associated with age in the ROAD study, a nationwide study of the Japanese population [29]. In that study, LSS was diagnosed using lumbar MRI, medical histories, and physical test performed by an orthopedic surgeon, and based on North American Spine Society guideline. The current study showed that the prevalence of LSS was $2.5 \%$ in men and $3.0 \%$ in women and increased with age. The prevalence of LSS was lower in our study than that in the ROAD study because the diagnostic tool used for LSS was different, wherein we used a selfadministered diagnostic support tool for LSS. However, the diagnostic support tool we used had good sensitivity (84\%) and specificity (78\%) for diagnosing LSS [12]. Thus, LSS prevalence in the current study was meaningful as a base data for screening. LSS prevalence increases with age according to past and current studies [29].

To the best of our knowledge, there has been no report on the comorbidity of $\mathrm{MCl}$ and LSS to date. The comorbidity rates of $\mathrm{MCl}$ and LSS were $0.8 \%$ and $2.1 \%$, respectively in those aged ${ }^{3} 65$ years in our study. The rate of $\mathrm{MCl}$ was $29 \%$ in participants with LSS, and the rate of LSS was $9.8 \%$ in participants with $\mathrm{MCl}$ in both sexes. The prevalence of $\mathrm{MCl}$ and LSS has been proven to increase with age, and the comorbidity 
rate of $\mathrm{MCl}$ and LSS also increased with age in this study. We showed a high rate of comorbidity of $\mathrm{MCl}$ and LSS, and one third of the people with LSS had MCI in a Japanese dwelling population. This study was held as part of a medical checkup program, and almost all subjects would be interested in health. Thus, the comorbidity rate of $\mathrm{MCl}$ and LSS may increase if people who are not interested in health and who cannot go outside because of decaying mobility capability were enrolled as subjects in a similar study. The percentage of elderly persons in Japan will highly increase in the future, suggesting that the comorbidity rate of $\mathrm{MCl}$ and LSS will correspondingly further increase. Hence, when we examine and treat people with LSS, we should always consider the cognitive impairment as a potential comorbidity.

\section{The relationship between LDD and cognitive function}

Several reports were showed the links between musculoskeletal disease and cognitive function previously. Baseline MMSE summary score and the prevalence of $\mathrm{MCl}$ were significantly associated with the incidence of knee osteoarthritis [10]. Delayed union of vertebral fracture decreased MMSE summary score in a longitudinal study [11]. However, to the best of our knowledge, there has been no report on LDD and cognitive impairment. This study is the first report showing that the presence of LSS, symptoms of LDD, and deterioration of QOL due to low back pain are associated with $\mathrm{MCl}$ and $\mathrm{MMSE}$ summary score.

Here, pain and numbness of lower limbs was associated with $\mathrm{MCl}$ and MMSE in men. The relationship between pain and cognitive impairment were also reported previously. Pain was a serious symptom secondary to neuropsychiatric symptoms in patients with dementia [30] and approximately $50 \%$ of people with dementia experienced pain regularly [31]. Chronic and neuropathic pain are particularly associated with cognitive impairment [7, 8]. A past report showed that severe pain led to cognitive impairment in a longitudinal study [3]. We showed that neuropathic pain and numbness due to LDD were associated with cognitive dysfunction. A few reports showed the difference of pain threshold between men and women. Calvo-Perxas [32] showed gender differences in depression and pain, and suggested that mild to severe pain showed an association with depression in men, although only severe pain was associated with depression in women. They suggested that the frequency of pain, rather than severity of pain, was related with the deterioration of the central nervous system in men. In our report, the symptoms of the lower limbs might be associated with cognitive function in only men because of gender differences in the central sensitization of pain.

Several reports have showed the relations between physical dysfunction and cognitive impairment. Gait speed, standing balance, stand-up time and leg strength declined more in cognitive impairment subjects compared with healthy subjects [1,33,34], and these physical functions decayed prior to cognitive decline [9]. In the current study, deteriorations of QOL, which were related with lumbar function and gait function, were associated with the prevalence of $\mathrm{MCl}$ in men and decline of MMSE scores in both sexes. Physical dysfunction may cause cognitive dysfunction through deterioration of QOL in people with LDD. The effect of intervention of pain and physical dysfunction on cognitive function is controversial. We should do an interventional study on whether LDD treatment also improves cognitive function. 


\section{Limitations}

There were several limitations to our study. First, we used only the MMSE for evaluating cognitive function. Although MMSE is a standard measure of cognitive function, MMSE could evaluate only global cognitive function. We should study the relationships between LDD and specific cognitive functions such as memory and language, among others. Second, although more than 1000 participants were included in this study, the study population may not be representative of the general population because participants were recruited from only one area of Japan. Further, we could not clarify the causal relationship between LDD and cognitive impairment because this was a cross-sectional study. Hence, a longitudinal study investigation, the causal relationship between LDD and cognitive function is necessary in the future.

Nevertheless, this is the first study to have investigated the relationship between LDD and cognitive impairment in a Japanese population to the best of our knowledge, and our results provide valuable information to improve QOL of elderly people in a super-aging society. This health promotion project started from 2005 and provides continuous data, enabling longitudinal study to clarify further relationships between LDD and cognitive impairment.

\section{Conclusions}

Our results indicated that the comorbidity rate of $\mathrm{MCl}$ and LSS was $0.8 \%$ in all participants, and $2.1 \%$ in those aged ${ }^{3} 65$ years, and this comorbidity rate increased along with age. Deterioration of QOL related to lumbar function and pain of lower limb were associated with $\mathrm{MCl}$ in men. Deterioration of QOL related to lumbar and gait function, and LSS presence were associated with summary score of MMSE in both sexes, while pain and numbness of lower limb were associated with summary score of MMSE in men. Treatment of LDD may be useful in bringing improvement of cognitive function.

\section{List Of Abbreviations}

LDD - Lumbar degenerative disease

LSS - Lumbar spinal stenosis

$\mathrm{MCl}$ - Mild cognitive impairment

QOL - Quality of life

VAS - Visual analog scale

JOABPEQ - Japanese Orthopedic Association Back-Pain Evaluation Questionnaire

MMSE - Mini Mental State Examination

\section{Declarations}




\section{Ethics approval and consent to participate}

For this cross-sectional survey, the ethics committee of Hirosaki University, Graduate School of Medicine approved the study, and all participants provided written informed consent before participation.

\section{Consent for publication}

Not applicable

\section{Availability of data and material}

The datasets used and/or analyzed during the current study are available from the corresponding author upon reasonable request.

\section{Competing Interests}

The authors declare that they have no competing interests.

\section{Funding}

This work was supported by JOA-Subsidized Science Project Research grant from the Japanese Orthopedic Association (No. 2015-2), and the Center of Innovation Program from Japan Science and Technology Agency.

\section{Authors' contributions}

Conceived and designed the experiments: $\mathrm{KK}, \mathrm{WK}, \mathrm{SN}, \mathrm{YI}$

Performed the experiments: KK, WK, GK, SO

Analyzed the data: KK, SO

Wrote the paper: KK, WK

Revised the paper critically for important intellectual content: GK, HK, ST, TA, KI, SN, YI

\section{Acknowledgement}

We would like to thank Editage (www.editage.com) for English language editing. 


\section{References}

1. Lyle MA, Manes S, McGuinness M, Ziaei S, Iversen MD. Relationship of physical examination findings and self-reported symptom severity and physical function in patients with degenerative lumbar conditions. Phys Ther. 2005;85:120-33.

2. Thornes E, Robinson HS, Vollestad NK. Degenerative lumbar spinal stenosis and physical functioning: an exploration of associations between self-reported measures and physical performance tests. Disabil Rehabil. 2018;40:232-7.

3. Kuittinen P, Sipola P, Saari T, Aalto TJ, Sinikallio S, Savolainen S, et al. Visually assessed severity of lumbar spinal canal stenosis is paradoxically associated with leg pain and objective walking ability. BMC Musculoskelet Disord. 2014;15:348.

4. Mitchell AJ, Shiri-Feshki M. Rate of progression of mild cognitive impairment to dementia--metaanalysis of 41 robust inception cohort studies. Acta Psychiatr Scand. 2009;119:252-65.

5. Ritchie K, Artero S, Touchon J. Classification criteria for mild cognitive impairment: a populationbased validation study. Neurology. 2001;56:37-42.

6. Roberts R, Knopman DS. Classification and epidemiology of MCl. Clin Geriatr Med. 2013;29:753-72.

7. Moriarty O, Ruane N, O'Gorman D, Maharaj CH, Mitchell C, Sarma KM, et al. Cognitive impairment in patients with chronic neuropathic or radicular pain: an interaction of pain and age. Front Behav Neurosci. 2017;11:100.

8. Povedano M, Gascon J, Galvez R, Ruiz M, Rejas J. Cognitive function impairment in patients with neuropathic pain under standard conditions of care. J Pain Symptom Manage. 2007;33(1):78-89.

9. Narazaki K, Matsuo E, Honda T, Nofuji Y, Yonemoto K, Kumagai S. Physical fitness measures as potential markers of low cognitive function in Japanese community-dwelling older adults without apparent cognitive problems. J Sports Sci Med. 2014;13:590-6.

10. Yoshimura N, Muraki S, Oka H, Kawaguchi H, Nakamura K, Tanaka S, et al. Does mild cognitive impairment affect the occurrence of radiographic knee osteoarthritis? A 3-year follow-up in the ROAD study. BMJ Open. 2012;2.

11. Takahashi S, Hoshino M, Tsujio T, Terai H, Suzuki A, Namikawa T, et al. Risk factors for cognitive decline following osteoporotic vertebral fractures: a multicenter cohort study. J Orthop Sci. 2017;22(5):834-9.

12. Aizawa T, Tanaka Y, Yokoyama T, Shimada Y, Yamazaki K, Takei H, et al. New diagnostic support tool for patients with leg symptoms caused by lumbar spinal stenosis and lumbar intervertebral disc herniation: a self-administered, self-reported history questionnaire. J Orthop Sci. 2016;21:579-85.

13. Folstein MF, Folstein SE, McHugh PR. "Mini-mental state". A practical method for grading the cognitive state of patients for the clinician. J Psychiatr Res. 1975;12:189-98.

14. Ciesielska N, Sokolowski R, Mazur E, Podhorecka M, Polak-Szabela A, Kedziora-Kornatowska K. Is the Montreal Cognitive Assessment (MoCA) test better suited than the Mini-Mental State Examination 
(MMSE) in mild cognitive impairment ( $\mathrm{MCl}$ ) detection among people aged over 60? Meta-analysis. Psychiatr Pol. 2016;50:1039-52.

15. Fukui M, Chiba K, Kawakami M, Kikuchi S, Konno S, Miyamoto M, et al. JOA Back Pain Evaluation Questionnaire (JOABPEQ)/JOA Cervical Myelopathy Evaluation Questionnaire (JOACMEQ). The report on the development of revised versions. April 16, 2007. The Subcommittee of the Clinical Outcome Committee of the Japanese Orthopaedic Association on Low Back Pain and Cervical Myelopathy Evaluation. J Orthop Sci. 2009;14:348-65.

16. Azimi P, Yazdanian T, Benzel EC. Determination of minimally clinically important differences for JOABPEQ measure after discectomy in patients with lumbar disc herniation. J Spine Surg. 2018;4:102-8.

17. Ogura Y, Ogura K, Kobayashi Y, Kitagawa T, Yonezawa Y, Takahashi Y, et al. Minimally clinically important differences for the Japanese Orthopaedic Association Back Pain Evaluation Questionnaire (JOABPEQ) following decompression surgery for lumbar spinal stenosis. J Clin Neurosci. 2019;69:93-6.

18. Komatsu J, Iwabuchi M, Endo T, Fukuda H, Kusano K, Miura T, et al. Clinical outcomes of lumbar diseases specific test in patients who undergo endoscopy-assisted tubular surgery with lumbar herniated nucleus pulposus: an analysis using the Japanese Orthopaedic Association Back Pain Evaluation Questionnaire (JOABPEQ). Eur J Orthop Surg Traumatol. 2020;30:207-13.

19. Kellgren JH, Lawrence JS. Radiological assessment of osteo-arthrosis. Ann Rheum Dis. 1957;16:494502.

20. Chiba D, Wada K, Tanaka T, Kumagai G, Sasaki E, Takahashi I, et al. Serum pentosidine concentration is associated with radiographic severity of lumbar spondylosis in a general Japanese population. $J$ Bone Miner Metab. 2017;35:65-72.

21. Cooper C, Sommerlad A, Lyketsos CG, Livingston G. Modifiable predictors of dementia in mild cognitive impairment: a systematic review and meta-analysis. Am J Psychiatry. 2015;172:323-34.

22. Rouch L, Cestac P, Hanon O, Cool C, Helmer C, Bouhanick B, et al. Antihypertensive drugs, prevention of cognitive decline and dementia: a systematic review of observational studies, randomized controlled trials and meta-analyses, with discussion of potential mechanisms. CNS Drugs. 2015;29:113-30.

23. Lee Y, Back JH, Kim J, Kim SH, Na DL, Cheong HK, et al. Systematic review of health behavioral risks and cognitive health in older adults. Int Psychogeriatr. 2010;22:174-87.

24. Beydoun MA, Beydoun HA, Gamaldo AA, Teel A, Zonderman AB, Wang Y. Epidemiologic studies of modifiable factors associated with cognition and dementia: systematic review and meta-analysis. BMC Public Health. 2014;14:643.

25. Wilson RS, Capuano AW, Boyle PA, Hoganson GM, Hizel LP, Shah RC, et al. Clinical-pathologic study of depressive symptoms and cognitive decline in old age. Neurology. 2014;83(8):702-9.

26. Ward A, Arrighi HM, Michels S, Cedarbaum JM. Mild cognitive impairment: disparity of incidence and prevalence estimates. Alzheimers Dement. 2012;8(1):14-21. 
27. Wada-Isoe K, Uemura Y, Nakashita S, Yamawaki M, Tanaka K, Yamamoto M, et al. Prevalence of dementia and mild cognitive impairment in the rural island town of Ama-cho, Japan. Dement Geriatr Cogn Dis Extra. 2012;2:190-9.

28. Baumgart M, Snyder HM, Carrillo MC, Fazio S, Kim H, Johns H. Summary of the evidence on modifiable risk factors for cognitive decline and dementia: a population-based perspective. Alzheimers Dement. 2015;11:718-26.

29. Ishimoto Y, Yoshimura N, Muraki S, Yamada H, Nagata K, Hashizume H, et al. Prevalence of symptomatic lumbar spinal stenosis and its association with physical performance in a populationbased cohort in Japan: the Wakayama Spine Study. Osteoarthritis Cartilage. 2012;20:1103-8.

30. Beerens HC, Sutcliffe C, Renom-Guiteras A, Soto ME, Suhonen R, Zabalegui A, et al. Quality of life and quality of care for people with dementia receiving long term institutional care or professional home care: the European RightTimePlaceCare study. J Am Med Dir Assoc. 2014;15:54-61.

31. Corbett A, Husebo B, Malcangio M, Staniland A, Cohen-Mansfield J, Aarsland D, et al. Assessment and treatment of pain in people with dementia. Nat Rev Neurol. 2012;8:264-74.

32. Calvo-Perxas L, Vilalta-Franch J, Turro-Garriga O, Lopez-Pousa S, Garre-Olmo J. Gender differences in depression and pain: a two year follow-up study of the Survey of Health, Ageing and Retirement in Europe. J Affect Disord. 2016;193:157-64.

33. Rosano C, Simonsick EM, Harris TB, Kritchevsky SB, Brach J, Visser M, et al. Association between physical and cognitive function in healthy elderly: the health, aging and body composition study. Neuroepidemiology. 2005;24:8-14.

34. Fitzpatrick AL, Buchanan CK, Nahin RL, Dekosky ST, Atkinson HH, Carlson MC, et al. Associations of gait speed and other measures of physical function with cognition in a healthy cohort of elderly persons. J Gerontol A Biol Sci Med Sci. 2007;62:1244-51. 